\title{
Fenomenología
}

\section{Um enfermeiro presidente da República. Você sabia?}

\section{A nurse president of the Republic. Did you know?}

\section{¿Un enfermero presidente de la República. Usted lo sabía?}

Taka Oguissoㅜㄹ Lidia Monjane²; Ana Paula Faustino Gilio³; Genival Fernandes de Freitas ${ }^{4}$.

${ }^{1}$ Enfermeira. Professora Titular do Departamento de Orientação Profissional da Escola de Enfermagem da Universidade de São

Paulo - EEUSP (aposentada). Presidente da Academia Brasileira de História da Enfermagem - ABRADHENF, $2012-2014$.

${ }^{2}$ Enfermeira. Professora do Instituto Superior de Ciências da Saúde (ICISA), Maputo. Doutoranda do programa de pós-graduação da Escola Paulista de Enfermagem, da Universidade Federal de São Paulo (UNIFESP) 2010-2014, com bolsa de estudos da Fundação Ford. Ex-presidente da Associação Nacional dos Enfermeiros de Moçambique (ANEMO).

${ }^{3}$ Enfermeira graduada pela Escola de Enfermagem da Universidade de São Paulo (EEUSP).

${ }^{4}$ Enfermeiro. Professor Livre-docente e Doutor do Departamento de Orientação Profissional da Escola de Enfermagem da Universidade de São Paulo (EEUSP).

Cómo citar este artículo en edición digital: Oguisso, T; Monjane, L; Gilio, A.P.F ; Fernandes de Freitas, G. (2013) Um enfermeiro presidente da República. Você sabia? 17, 35. Disponible en: <http://dx.doi.org/10.7184/cuid.2013.35.02>

Correspondencia: Taka Oguisso. Departamento de Orientação Profissional da Escola de Enfermagem da Universidade de São Paulo - EEUSP

Av. Dr. Enéas de Carvalho Aguiar, 419. Cerqueira César

CEP - 05403-000 - São Paulo. Correo electrónico: takaoguisso@uol.com.br Recibido 20/12/2012. Aceptado 30/2/2013

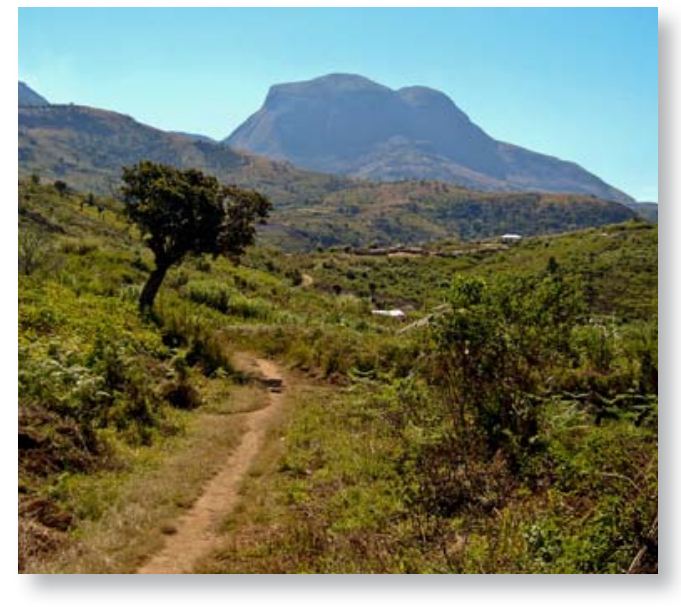

ABSTRACT

It describes Samora Machel's life, a Mozambican nurse, who led guerrillas until successfully obtaining the independence of the Republic of Mozambique. Reporting his life history and his role in the country's health, it is aimed at showing that politics can become a way of other nurses, in other countries, may also go through this path for the benefit of the whole population and through exercising leadership also contribute to improve health and living conditions of the communities. Besides fighting against racism, discrimination, illiteracy, poverty and drought during his more than 10 years in the government, Samora Machel had to fight internally against opponent political forces. Anyway, he was an example for his country where he is reverenced and venerated as a national hero.

Key words: Life history, History of Mozambique. Nursing history.

\section{RESUMEN}

Se describe la vida de Samora Machel, un enfermero mozambiquo que lideró guerrillas hasta obtener la independencia del país y crear la República de Mozambique. Reportar su his- 
toria de vida y su rol en la salud de su país, es el objetvo de este trabajo. Demostrar que la política puede ser un medio para que otros enfermeros, en otros países, puedan también seguir este camino para el beneficio de toda una población y a través del ejercicio de liderazgo puedan contribuir para mejorar la salud y las condiciones de vida de la comunidad. Además de luchar contra el racismo, discriminación, analfabetismo, la miseria y la sequía, durante los más de 10 años al frente de su gobierno, Samora Machel, aún tuvo que luchar internamente contra fuerzas políticas oponentes. De todas manera, fue un ejemplo en su país, donde es reverenciado y venerado como un héroe nacional.

Palabras clave: historia de vida, historia de Mozambique, historia de la enfermería.

\section{RESUMO}

Descreve a vida de Samora Machel, um enfermeiro moçambicano, que liderou guerrilhas até obter a independência e criar a República de Moçambique. Narrar sua história de vida e seu papel na saúde de seu país, tem por objetivo mostrar que a política pode ser um meio para que outros enfermeiros, em outros países, possam também seguir por esse caminho para o beneficio de toda uma população e através do exercício da liderança, também contribuir para melhorar a saúde e as condições de vida das comunidades. Além de lutar contra o racismo, a discriminação, o analfabetismo, a pobreza e a seca durante mais de dez anos em seu governo, Samora Machel teve que lutar internamente contra forças políticas oponentes. De qualquer modo, ele se tornou um exemplo em seu país onde é reverenciado e venerado como herói nacional.

Palavras chave: História de vida, História de Moçambique, História da Enfermagem.

\section{INTRODUÇÃO}

$\mathrm{O}$ interesse pela vida de um enfermeiro e líder moçambicano surgiu, inicialmente, em palestras de conteúdo sobre História da Enfermagem quando se discutia sobre um enfermeiro que havia sido Presidente da República, fato raro e inusitado na historiografia da enfermagem em geral. Tal fato ocorrido na República de Moçambique despertava grande interesse e curiosidade em conhecer melhor essa figura e como ascendeu a essa posição de destaque nacional.

Moçambique é um país situado na costa oriental austral do continente africano, tendo ao norte a Tanzânia, a noroeste Malaui e Zâmbia, a oeste Zimbábue, ao leste é limitado pelo Canal de Moçambique e o Oceano Indico e ao sul tem a África do Sul e Suazilândia. Sua moeda é chamada metical e tem uma população de quase 24 milhões de habitantes, segundo dados de 2011. O navegador português Vasco da Gama passou por essa região em 1498, em sua expedição em busca do caminho marítimo para as Índias. Embora os portugueses tenham tomado posse da região costeira em 1505, somente em 1885 a penetração portuguesa - com a partilha da Africa pelas potências européias durante a Conferência de Berlim - se transformou numa ocupação militar, com a submissão dos estados ali existentes, o que levou, no início do século XX a uma verdadeira administração colonial (Sopa, 2001). É país de língua oficial portuguesa e tornou-se independente de Portugal no dia 25 de junho de 1975. A maior cidade é Maputo, sua capital.

Esse estudo pôde ser desenvolvido graças a alguns intercâmbios com lideres da enfermagem moçambicana e posterior vinda a São Paulo para estudos de pós-graduação de uma enfermeira moçambicana, ex-presidente da Associação Nacional de Enfermeiros de Mo- 
çambique (ANEMO), e professora do Instituto de Educação em Enfermagem.

Em Maputo encontra-se o centro político, financeiro, industrial, comercial e mercantil do país. A capital foi fundada em 1782, com o nome de Lourenço Marques, comerciante português que se radicara na cidade. Passou a denominar-se Maputo, após a independência, em fevereiro de 1976, para lembrar a fronteira sul do país marcado pelo Rio Maputo. Moçambique tem sua costa marítima banhada pelo Oceano Indico, e Maputo é conhecido também como a Pérola do Indico.

Assim, este trabalho pretende descrever um pouco da cultura, história, condições de saúde e do cotidiano, em geral, de Moçambique com base nas referências bibliográficas além de experiências colecionadas em viagens efetuadas por duas das autoras deste estudo, e posteriormente enriquecidas pela vivência de uma enfermeira, autêntica líder moçambicana, que se encarregou de fazer atualização de dados e outras observações ao texto.

São, portanto, objetivos deste trabalho, divulgar a história de vida de um personagem, o enfermeiro Samora Machel, e contribuir para que enfermeiros encontrem num trabalho político criterioso e honesto um caminho para a expansão do espaço profissional e maior valorização desses profissionais pela sociedade.

\section{CAMINHOS PARA A INDEPENDÊNCIA DE MOÇAMBIQUE}

O movimento nacionalista surgiu na década de 1950 e ganhou impulso em 1962, com a criação da Frente de Libertação de Moçambique (FRELIMO), mas, oficialmente, a guerra da independência teve início no dia 25 de setembro de 1964, com um ataque ao posto administrativo de Chai no então distrito (atual província) de Cabo Delgado. E, terminou com

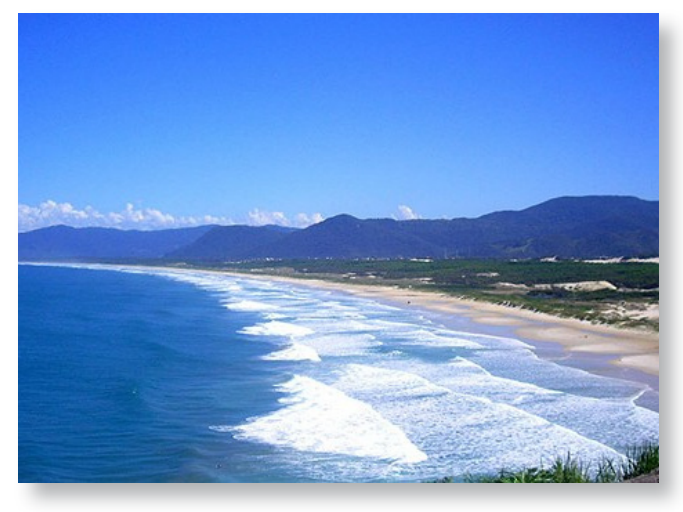

um cessar-fogo no dia 8 de Setembro de 1974, resultando numa independência negociada em junho de 1975.

Ao longo de quatro séculos de presença em território africano, a primeira vez que Portugal teve que enfrentar guerras de independência, e forças de guerrilha, foi em 1961, na Guerra de Independência de Angola. Em Moçambique, o conflito começou em 1964, resultado da frustração e agitação de cidadãos moçambicanos, contra a forma de administração estrangeira, considerada exploradora e que infligia maus tratos, defendendo apenas os interesses econômicos portugueses na região.

Muitos moçambicanos ressentiam-se das políticas portuguesas em relação aos nativos, que eram discriminatórias, tradicionais e limitavam o acesso à educação e ao emprego qualificado. Um exílio em massa de políticos de Moçambique para países vizinhos, especialmente a Tanzânia, proporcionou-lhes ambiente ideal, onde radicais moçambicanos podiam planejar ações e criar agitação política, no seu país de origem. A criação da organização de guerrilha moçambicana FRELIMO e com o apoio da União Soviética, China e Cuba, que forneciam armamento e instrutores, levaram ao surgimento da violência que continuaria por mais uma década.

Esses movimentos de libertação eram liderados por Eduardo Mondlane, um dos primei- 
ros negros moçambicanos a obter grau universitário. Mondlane foi assassinado em 1969 por uma encomenda-bomba e, em maio de 1970, foi substituído por Samora Machel, em eleição do Comitê Central, da FRELIMO. Posteriormente, com a independência, Samora Machel tornou-se o primeiro presidente da República de Moçambique e o maior herói da história moçambicana.

Essa figura histórica era enfermeiro, daí a curiosidade e interesse em melhor conhecer a trajetória de vida desse herói nacional, pois se trata do único enfermeiro que chegou ao cargo de mandatário máximo de um país, nele permanecendo por mais de dez anos. Tal fato, embora oficial em Moçambique é pouco conhecido na história da enfermagem mundial (Carnegie, 1995).

Quem sabe, sua história possa inspirar futuros enfermeiros para que trilhem os caminhos que levem a conquistar ou aumentar espaços políticos para a profissão.

\section{SISTEMA EDUCACIONAL EM MOÇAM- BIQUE}

O Sistema Nacional de Educação (SNE) de Moçambique foi inicialmente aprovado em 1983 e atualizado pela Lei de 1992 (Lei no 06, de 06-05-1992), em vigor. O ensino encontra-se estruturado em pré-escolar, escolar e extra-escolar. Em síntese, pode-se dizer que o ensino pré-escolar realiza-se em creches e jardins da infância para crianças com idade inferior a 6 anos como complemento à ação educativa da família. O ensino escolar compreende: o ensino geral, o técnico profissional e o superior.

O ensino geral constitui o eixo central do SNE e confere formação integral e politécnica e pode ser feito em instituições estatais, cooperativas, comunitárias ou privadas. $\mathrm{O}$ ensino geral compreende os níveis: primário e secun- dário. $\mathrm{O}$ ensino primário é frequentado por crianças a partir dos 6 anos de idade e tem a duração de sete anos, subdivididos em: $1^{\circ}$ grau da $1^{\text {a }}$ à $5^{\mathrm{a}}$ classe; e, $2^{\circ}$ grau, a $6^{\mathrm{a}}$ e $7^{\mathrm{a}}$ classe. Cada ano letivo de escolarização com dois semestres letivos, iniciados em fevereiro de cada ano, é chamado de classe. O ensino secundário

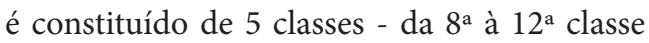
e subdivide-se em dois ciclos: $1^{\circ}$ ) da $8^{\mathrm{a}}$ à $10^{\mathrm{a}}$ classe e o $\left.2^{\circ}\right) 11^{\mathrm{a}}$ e $12^{\mathrm{a}}$ classe. Ao final de cada ano ou classe do ensino secundário, o aluno recebe um certificado de conclusão dessa classe. Concluintes da $12^{\mathrm{a}}$ classe podem ingressar em universidades ou em instituto superior de ciências ou politécnicos.

$\mathrm{O}$ ensino técnico-profissional constitui o principal instrumento para a formação profissional da força de trabalho qualificada. Este compreende os seguintes níveis: elementar, básico e médio. Para o ingresso no nível elementar é exigida a conclusão do $1^{\circ}$ grau do ensino geral primário; para o ingresso no nível básico, a conclusão do $2^{\circ}$ grau do ensino primário geral e para o nível médio a conclusão do $1^{\circ}$ ciclo do ensino secundário geral ou ensino básico técnico-profissional.

Para atender necessidades especificas na área da assistência preventiva, o país criou o ensino profissionalizante na área da saúde, com formação em nível elementar, básico, médio, médio especializado e superior. Para ingressar no curso elementar técnico de saúde o candidato deve ter concluído a $7^{\text {a }}$ classe do ensino primário geral e frequentar um curso de 12 meses. Até recentemente bastava ter completado a $5^{\text {a }}$ classe. Para fazer um curso básico técnico, de 18 meses de duração, o requisito de ingresso é a conclusão da $10^{\text {a }}$ classe. O nível médio pode ser alcançado também via curso de promoção, com duração de um ano. Os candidatos devem ser profissionais de saú- 
de de nível básico com o mínimo de dois anos de trabalho como profissionais de saúde.

O curso de enfermagem, de nível médio profissional, tem duração de dois anos letivos. O concluinte desse curso, após dois anos de exercício como profissional da saúde, pode fazer uma especialização, como anestesista, instrumentista, técnico em cirurgia. Esses cursos têm a duração de 18 meses a 2 anos de estudos, conforme a especialidade. Assim, todos os profissionais têm possibilidade de progressão na carreira, bastando para tanto preencher o requisito de escolaridade exigido para cada nível e fazer os cursos específicos.

Profissionais de formação em nível médio e médio especializado têm substituído os formados de nível superior dessas mesmas áreas, em locais onde haja falta dessas especialidades. Por exemplo, o técnico de cirurgia e a enfermeira de saúde materna estão capacitados a realizar pequenas cirurgias, como extração de cistos, lipomas, outras desse porte e cesarianas. $\mathrm{O}$ nível superior confere graus de licenciado e na pós-graduação, graus de mestrado e doutorado.

Atualmente, existem em Moçambique cursos de enfermagem em nível superior oferecidos pelas seguintes instituições: Instituto Superior de Ciências da Saúde (ICISA), subsidiado pelo governo; os seguintes são de natureza privada: Instituto Superior Politécnico (ISPU); Universidade Católica de Moçambique; Instituto Superior de Ciência e Tecnologia (ISCTEN) e Universidade Lúria (UniLúria), localizada em Nampula, ao norte do país. Em todos os cursos, privados ou não, os alunos pagam as respectivas mensalidades. Não há ensino totalmente gratuito em nível superior, pois mesmo os subsidiados pelo governo, estudantes contribuem para sua aprendizagem. Para ingresso no curso superior o candidato deverá ter completado a $12^{\text {a }}$ classe de estudos, ou doze anos de estudos prévios, e prestar provas de concurso para ingresso (no Brasil corresponde ao exame vestibular). Candidatos para a área de enfermagem prestam concurso em biologia e português.

Segundo dados e projeções do Ministério da Saúde de Moçambique (MSM, 2011), em 2012, havia aproximadamente 1.000 (hum mil) médicos nacionais em atividade no país, além de 250 médicos estrangeiros, procedentes de Cuba, China e Coréia do Norte, e 9.502 profissionais de enfermagem, além de cerca 72 mil curandeiros, que cumpriam o papel de guia espiritual e de médicos nos distritos mais afastados das 11 províncias.

\section{ORIGENS DE UM HERÓI}

Samora Moisés Machel, do grupo étnico Shangana, nasceu em 29 de setembro de 1933 e foi criado na vila de Xilembene, província de Gaza, em Moçambique. Seus pais eram camponeses que cultivavam algodão. Sua mãe teve dez filhos, mas somente três sobreviveram. Ingressou numa escola católica, e aos dezessete anos concluíra a quarta classe. Em 1951 iniciou os estudos para ser enfermeiro, uma das poucas profissões permitidas aos negros moçambicanos pelo sistema colonial. Para ingressar no curso de enfermagem, na época, bastava completar a $4^{\text {a }}$ serie do ensino primário. Ao concluir o curso de enfermagem, não satisfeito com sua formação geral, tratou de fazer estudos secundários no ensino particular.

Ao mesmo tempo foi trabalhar num hospital, onde iniciou suas primeiras atividades políticas ao protestar pelo fato de enfermeiros negros receberem salário inferior ao dos brancos que faziam o mesmo trabalho. Mais tarde disse a um repórter o quanto os médicos moçambicanos eram maltratados dizendo, "o cão 
do homem rico recebe mais vacinas, medicamentos e cuidados médicos do que os trabalhadores que constroem a riqueza do homem rico" (Sopa, 2011).

Em 1956, foi designado para trabalhar como enfermeiro na ilha de Inhaca, nas proximidades da cidade de Maputo, onde se casou com Sorita Tchaicomo e tiveram quatro filhos. Poste-

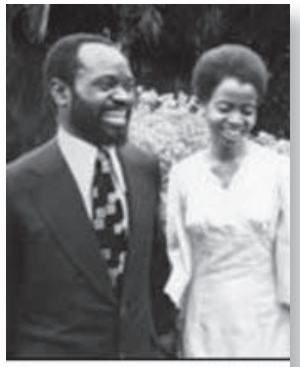

Samora e Graça Machel riormente, em 1969, casou-se com Josina

Muthemba, com quem teve um filho chamado Samora Machel Jr. Casou-se pela terceira vez, em 1977, já como Presidente da República, com Graça Simbine, que era ministra da educação (Sopa, 2011). Atualmente Graça Machel é presidente de uma das maiores organizações não governamentais (ONG) de Moçambique, a Fundação para o Desenvolvimento da Comunidade.

\section{LÍDER REVOLUCIONÁRIO}

Em 1963, Samora Machel ingressou na FRELIMO, quando foi se juntar aos irmãos, na Tanzânia. Assim, o jovem enfermeiro Samora Machel foi integrado num grupo de recrutas e recebeu treinamento militar na Argélia. Em 1964, retornou a Moçambique e guiou a FRELIMO para a sua primeira guerrilha contra os portugueses no norte de Moçambique. Em maio de 1970, após a morte de Eduardo Mondlane, Samora Machel assumiu a presidência da FRELIMO e começou a ser conhecido no cenário político.

Samora continuou a liderar a FRELIMO durante a luta pela independência, derrotando o exército colonial e libertando soldados por- tugueses que a guerrilha fizera prisioneiros e conseguiu conquistar progressivamente o território onde se organizavam as populações nas zonas libertadas e desde então passou a ser reconhecido como o homem que conduziu Moçambique à proclamação total e completa da independência.

Atualmente, os cidadãos de Moçambique referem-se ao líder como alguém que sempre se posicionou contra o colonialismo português e nunca contra o povo português, nem contra os brancos.

Em sete de setembro de 1974, na praia do Tofo (Inhambane), foi aprovada a Constituição da República Popular de Moçambique e decidido que Samora Machel seria o Presidente da República.

Após a independência, a FRELIMO tornou-se um partido político e passou a apoiar o governo no poder e a guiar os destinos do país. A FRELIMO permanece no poder até hoje, tendo sido vitoriosa nas quatro eleições multipartidárias realizadas em 1994, 1999, 2004 e 2009.

\section{A Presidência de Samora Machel}

Samora Machel se manteve na presidência do país desde 1975 até à sua morte em outubro de 1986. Ele sempre assumiu uma política populista, tentando angariar o apoio do povo para o desenvolvimento do país em base socialista.

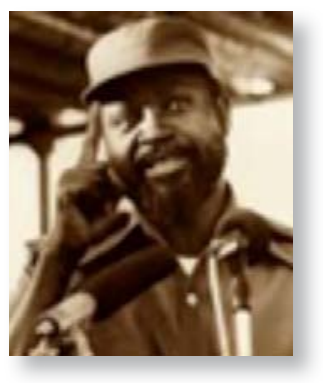

Samora Machel Guerrilheiro

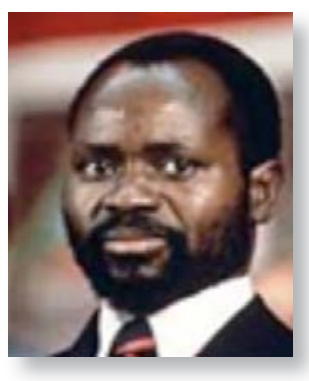

Samora Machel Presidente da República 
Menos de um mês depois da independência, a 24 de julho de 1975, Samora anunciou a nacionalização da Saúde, Educação e Justiça. Conseguiu o apoio popular, principalmente dos jovens, para operações de grande vulto, tal como a troca da moeda colonial pela nova moeda nacional chamada Metical.

Outras políticas populares foram as "ofensivas" a favor do aumento da produtividade e contra a corrupção, geralmente anunciadas em grandes comícios, com grande participação da população. No entanto, poucas destas campanhas tiveram êxito, porque fez com que grande número de residentes de origem estrangeira abandonasse o país, o que provocou a paralisação temporária de muitas empresas e mais tarde, também, por falta de capacidade de gestão levou ao colapso de muitos setores, tais como a indústria têxtil, metalúrgica e química.

Um dos problemas mais graves enfrentados por Samora Machel em todo o seu governo foi a guerrilha da Resistência Nacional Moçambicana (RENAMO), grupo de oposição, criado em 1977, no sul da Rodésia, atual Zimbabwe, supostamente apoiado pelo governo branco da África do Sul. Além das guerrilhas desse grupo de Resistência, de dezesseis anos de duração, o país enfrentou também uma década de seca a partir de 1983. Esses dois eventos devastaram a nação, mataram milhões de moçambicanos, deixaram milhares de minas terrestres, que continuaram a matar e ferir civis mesmo após o acordo de cessar fogo entre esses dois grupos, em 1992, e provocaram a fome em grande escala, a miséria generalizada e a incidência de epidemias de tifo e cólera.

Em 1993, com o cessar fogo entre os dois grupos, a Organização das Nações Unidas (ONU) interveio para introduzir uma operação de paz e os refugiados começaram a retornar ao país.
Samora Machel foi morto num acidente de avião em 19 de Outubro de 1986, em Bunzine, território Sul Africano e sucedido por Joaquim Chissano. Embora, muitos anos antes Samora Machel tivesse assinado um pacto de não agressão com o governo da Africa do Sul, a maioria dos moçambicanos ainda acredita que governantes desse país tivessem envolvimento com a queda do avião em que ele viajava. Sua viúva, Graça Machel, casou-se, anos mais tarde, em 1998, com Nelson Mandela, presidente da Africa do Sul de 1994 a 1999. Tornou-se um caso único no mundo, pois foi primeira-dama em dois paises.

\section{Graça Machel}
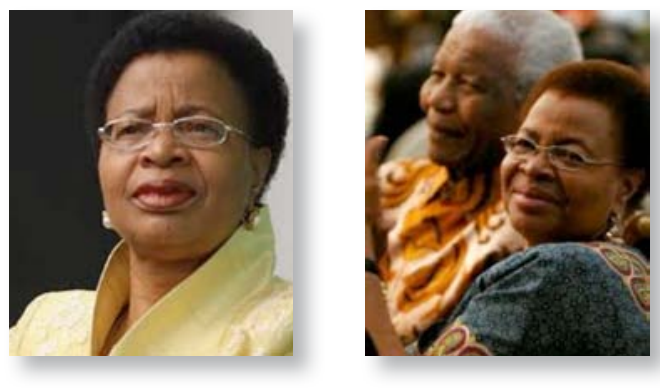

\section{SAMORA MACHEL E A SAÚDE NO PERÍ- ODO PÓS-INDEPENDÊNCIA}

A primeira grande medida de Samora Machel como presidente da República de Moçambique, em função da Política de Saúde, foi a nacionalização da medicina. Esta medida foi consubstanciada pelo Decreto-lei $n^{\circ} 31$, de 20 de julho de 1975, que nacionalizou a medicina e interditou qualquer forma de atividade sanitária a título privado ou lucrativo.

A Constituição da República criou um Serviço de Saúde para a população. O obstáculo era capacitar o Serviço de Saúde do Estado, pois ao nacionalizar a medicina privada e interditar o exercício em consultório pri- 
vado, o Estado precisaria estar em condições de assumir o Serviço e de atender a todos nas unidades sanitárias estatais, gratuitamente ou a preços acessíveis para a população. Mas, a herança colonial era muito forte e o Estado estava depauperado com a fuga do capital e dos técnicos da era colonial.

Com a independência e a retirada dos portugueses de Moçambique, o país contava com um número muito reduzido de médicos e enfermeiros moçambicanos. E receava-se que não houvesse compreensão para as dificuldades existentes, pois a expectativa popular era que, com a independência, haveria progresso em todos os setores, inclusive no setor de saúde.

Segundo depoimentos dos profissionais da saúde de Moçambique, a insuficiência de médicos para atender a demanda da população, levou a atuação dos enfermeiros a se tornar essencial no atendimento à população.

A partir da consciência de que a saúde era dever do Estado e direito do cidadão, foram elaboradas propostas como a medicina preventiva; a prioridade às zonas rurais e comunidades organizadas; a prioridade à saúde dos trabalhadores; a extensão da rede de cuidados de Saúde Materno-Infantil e dos programas de vacinação; o desenvolvimento da luta contra doenças transmissíveis, em particular, contra doenças tropicais; a participação comunitária

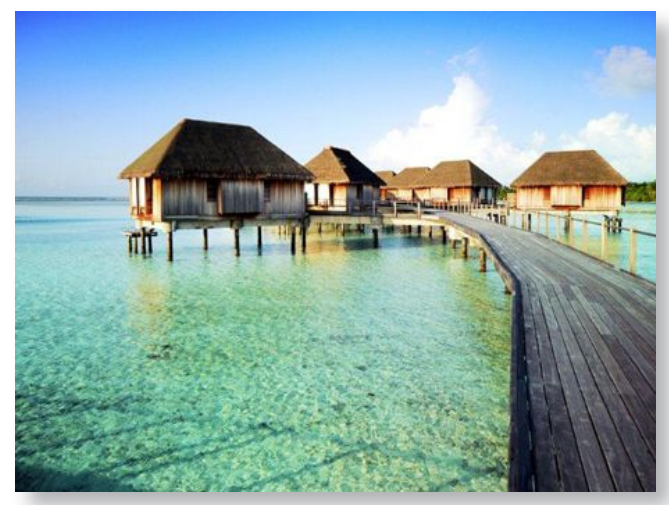

para a saúde, a reorganização e desenvolvimento das carreiras profissionais e dos programas de formação para acesso a essas carreiras e progressão nelas.

Samora Machel optou pela nacionalização imediata, o Serviço de Saúde deveria ser idêntico e gratuito para todos os cidadãos, e a saúde era dever do Estado.

Em pouco mais de dois anos, o quadro de pessoal do Serviço Nacional de Saúde que era de 2.500 trabalhadores, em 1975, passou para 10.500 trabalhadores em 1977, e com o resultado do processo formativo, para cerca de 11.500 trabalhadores em 1979.

No final de outubro de 1975, poucos meses depois da independência do país, foi realizado o I Seminário Nacional de Saúde, em Quelimane (Província da Zambézia), o qual teve como pauta principal o capital financeiro insuficiente para o novo planejamento em saúde (Martins, 2001).

Diante desta dificuldade, a Organização Mundial de Saúde (OMS) evidenciou a importância da participação comunitária para a saúde. Adotou como medida mobilizar a população para a defesa de sua própria saúde, fazendo as pessoas participarem em ações não médicas de promoção da saúde. A essa medida, deu-se o nome de "Medicina Promotiva".

A população, incluindo a classe médica, apresentou resistência à Medicina Promotiva em função das novas ideias, as quais priorizavam ações preventivas aos medicamentos e intervenções cirúrgicas.

O Ministério da Saúde propôs duas campanhas principais:

- A campanha Nacional de Saneamento do Meio Ambiente, executada em todo território nacional, sob a liderança do presidente e com o envolvimento de todas as estruturas do governo aos diversos níveis (nacional/central, pro- 
vincial, distrital e local). Através desta campanha a população das regiões, que até setembro de 1974, estava sob a dominação colonial, participou pela primeira vez de forma organizada, na promoção da sua própria saúde.

- Lançamento do principio das vacinações sistemáticas como base da Política de Saúde, com uma Campanha Nacional de Vacinação que, em três anos, passou a cobrir $96 \%$ (noventa e seis) da população.

Samora Machel teve um papel muito importante no desenvolvimento dessas ideias. Deu ênfase à colaboração dos Governadores Provinciais. Durante a Campanha Nacional de Saneamento houve duas jornadas nacionais para cavar latrinas. O próprio Samora Machel ajudou a cavar e a construir latrinas e os ministros foram escalados para fazer o mesmo nas diversas províncias.

O I Seminário Nacional de Saúde demonstrou a organização do Serviço Nacional, e foram traçadas as primeiras orientações para o desenvolvimento da rede sanitária fora dos centros urbanos. Esta iniciativa de construção de latrinas continuou sendo seguida pelos novos governos como uma das formas de reduzir a alta incidência de epidemias. $\mathrm{O}$ desafio era, além da construção, inserir a prática de uso de latrinas pela população rural, maior vítima das doenças pela falta de saneamento. Neste trabalho tem sido fundamental a atuação dos enfermeiros, que são, na pratica, os profissionais que estão mais próximos da população nas zonas rurais.

Supõe-se que o fato de Samora Machel ter sido enfermeiro antes de se integrar à FRELIMO, influenciou suas medidas enquanto presidente, dando atenção especial aos Serviços de Saúde. Ele continua sendo extre- mamente amado, respeitado e reverenciado no país, por todas as camadas sociais, devido às medidas para melhorar a vida da população moçambicana e considerada figura muito importante nas mudanças de saúde no país após a independência.

Para implementação das medidas adotadas para melhoria da saúde, o presidente-enfermeiro expandiu a rede de centros de saúde por todo o país, principalmente nas localidades mais distantes, onde ao lado dos centros de saúde, construiu casas para enfermeiros. $\mathrm{Na}$ maioria dos lugares, estes profissionais eram (e continuam sendo) os principais pontos de apoio da população em muitos quilômetros.

Por último, cabe destacar que enfermeiros moçambicanos, conscientes da necessidade de se unirem e se fortalecerem, criaram a Associação Nacional de Enfermeiros Moçambicanos (ANEMO) em dezembro de 1990. Foi a primeira organização profissional do setor saúde no país. Solicitaram e obtiveram filiação ao Conselho Internacional de Enfermeiras (CIE) em 1993 (Oguiso, 1995). Samora Machel foi eleito membro honorário. Enfermeiros de países escandinavos mantiveram por muito tempo trabalhos de parceria com a ANEMO, auxiliando materialmente a suprir necessidades, através de suas organizações de classe. Suecos adquiriram terrenos e construíram algumas casas para enfermeiros na cidade de Beira, e noruegueses adquiriram uma casa em Maputo para servir de sede à ANEMO.

\section{CONSIDERAÇÕES FINAIS}

Ao conhecer a vida de Samora Machel, visualiza-se um profissional da saúde que se envolveu em questões político-sociais e econômicas, chegando a ser Presidente da República. Além de relatar sua biografia exemplar pretendia-se também demonstrar a importância da consciência política de saúde e de 
cidadania de um líder ao governar o destino de uma nação.

Em todos os cidadãos do país percebe-se a valorização deste grande líder histórico, e a admiração dos profissionais da enfermagem por Samora Machel. Entende-se que o fato de ter se formado e exercido a profissão, influenciou para que, durante seu governo, tivesse um envolvimento maior com as questões de saúde do país.

Assim, um enfermeiro chegou ao cargo mais alto, o de Presidente da República. Quem poderá ser o próximo? Em que país? Esperamos que a História possa responder a essa pergunta. Já constatamos que é possível, sim, mas é preciso muita dedicação e força de vontade para trabalhar por um grupo, uma comunidade ou um país, aliadas a uma forma de liderança que impulsione pessoas a realizarem um trabalho coletivo em busca de ideais bem definidos. Alguns países vizinhos, como Tanzânia, Zimbábue e Namíbia, também prestaram homenagem a este líder africano, morto prematuramente, dando seu nome a avenidas principais em suas capitais (Oguisso, 1995).

Finalmente cabe destacar que Florence Nightingale valeu-se muitas vezes do caminho político para alcançar seus intentos. A própria ida ao cenário da Guerra da Criméia (18531856) foi resultado de seu relacionamento pessoal com Sidney Herbert, Ministro da Guerra da Grã Bretanha na ocasião. Florence demonstrou no decorrer de seu trabalho nessa Guerra, e mesmo depois dela, que "os enfermeiros não podem estar afastados da atividade política, sob pena de não conseguirem as reformas necessárias para a prestação de bons cuidados à saúde” (Soares y Freitas, 2001). Corroborando com essa idéia, saliente-se que o caminho político pode encurtar o tempo por constituir-se em um verdadeiro atalho para a conquista de maior espaço para a enfermagem e para que ela seja cada vez mais valorizada pela sociedade (Oguisso, 2007).

\section{REFERÊNCIAS}

- Sopa, A. Coord. (2001) Samora - homem do povo. Mabuko Ltda: Maputo, Moçambique.

- Carnegie, M.E. (1995) The path we thread - blacks in nursing worldwide, 1854-1994. National League for Nursing Press, New York: 249-50.

- Moçambique. Lei n. 6, de 06-05-1992. Reajustar o quadro geral do sistema educativo e adequar as disposições contidas na Lei 04/83, de 23-03-1983, do Sistema Nacional de Educação, às atuais condições sociais e econômicas do país. Boletim da República de Moçambique. N. 104(8), Série I, n. 19.

- MSM (2011) Ministério da Saúdede Mozambique, Direção de Recursos Humanos, Relatório anual de 2010.

- Martins, H. (2001) Samora e a saúde (1975-80). In: Sopa A, organizador. Samora - homem do povo. Mabuko Ltda: Maputo, Moçambiqu: p. 117-25.

- Oguisso, T. (1995) Field visit report to the National Nurses Association of Mozambique, 17-24 June 1992. International Council of Nurses, ICN/92/95.

- Soares, M.I., Freitas, M.V. (2001) Florence Nightingale 1820-1910. Enfermagem. 21, (2ª série).

- Oguisso,T. (2007) Florence Nightingale. In: Oguisso, T. Trajetória histórica e legal da enfermagem. $2^{\mathrm{a}}$ ed, Barueri, Ed Manole, São Paulo: 58-97.

- Imagens de Samora Machel e Graça Machel - fonte http:// www.google.com.br. Acessado em 04-03-2013. 